\title{
Mitigating Risks in Inappropriate Handling of Chemicals by Small-Scale Textile Producers in Sekondi-Takoradi, Ghana
}

\author{
Eric Bruce-Amartey Jnr., Richard Acquaye* (1) \\ Department of Textile Design and Technology, Takoradi Technical University, Takoradi, Ghana \\ Email: *richard.acquaye@ttu.edu.gh
}

How to cite this paper: Bruce-Amartey Jnr., E. and Acquaye, R. (2022) Mitigating Risks in Inappropriate Handling of Chemicals by Small-Scale Textile Producers in Sekondi-Takoradi, Ghana. Journal of Textile Science and Technology, 8, 1-14. https://doi.org/10.4236/jtst.2022.81001

Received: December 11, 2021

Accepted: February 5, 2022

Published: February 8, 2022

Copyright (c) 2022 by author(s) and Scientific Research Publishing Inc. This work is licensed under the Creative Commons Attribution International License (CC BY 4.0).

http://creativecommons.org/licenses/by/4.0/

\begin{abstract}
Textile chemicals such as dyes, printing pigments, additives, oxidising agents and reducing agents can be very injurious to the body and the environment if not properly used. The prime focus of this study is to promote and maintain a safe and healthy environment by ensuring the highest level of environmental health and safety assistance for small scale textile dyers and chemical suppliers within the Sekondi-Takoradi Metropolitan Area of Ghana. Case Study, a descriptive research approach is used because data came mainly from archives, library and by direct observation of textile production practices at the small-scale level. The population for the study involved batik producers, tiedye producers, screen printers and textile chemical suppliers and dealers. Interviews and observations were used in soliciting relevant data. Data collected was analysed and presented. The study suggests appropriate ways of working with dyes and other chemicals for dyeing. It also simplified information on the available Material Safety Data Sheets (MSDS) for the understanding of the textile producers. This was tailored towards improving communication with the small-scale textile producers who collectively constitute a big percentage of textile producers in Ghana.
\end{abstract}

\section{Keywords}

Safety, Textile Chemicals, Dye, MSDS

\section{Introduction}

Small-scale textile production engages about 320 people in the Sekondi Takoradi Metropolis [1]. Textile products in the sector range from batik, tie-dye, tritik, plangi, ikat, screen printing; they also include sales of fabrics, dyes and textile 
chemicals. A very significant quantity of dyes and chemicals are used within the industry. Examples of dyes used are vat, reactive, disperse, natural dyes and printing pigments. Some examples of chemicals and additives used are soda ash, sodium hydrosulphite, sodium hydroxide, salt, hydrogen peroxide, sulphuric acid and paraffin wax. [2] [3] [4] contend that there are a number of health and environmental hazards that are associated with the usage of the dyes and their auxiliary chemicals. And chemical dealers and dyers are those who directly handle these chemicals and are highly exposed. The hazards include the exposure of the chemicals during the processing and dyeing of textile materials which affects the throat and lungs, and also leads to muscle skeletal stresses.

The most common hazard of reactive dyes is respiratory problems which are caused by the inhalation of dye particles. Sometimes this affects a person's immune system, and in extreme cases, this means that when the person inhales the dye again his body can react negatively. This hazard or ailment is called respiratory sensitisation and the associated symptoms may include itching, watery eyes, sneezing and also symptoms of asthma such as coughing and wheezing [5]. It has been established that the most prevalent health problems associated with dyeing and finishing processes arise from exposure to chemicals acting as irritants. Exposure to chemicals and irritants may cause skin irritation, itchy or blocked noses, sneezing and eye sores. Chemicals exposed to workers may include formaldehyde-based resins, ammonia, acetic acid, some shrink-resist chemicals, some optical whiteners, soda ash, caustic soda and bleach. Certain reactive, vat and disperse dyes have also been recognized as skin sensitisers [6].

Fire outbreak is a common hazard that may emanate from the use of flammable liquids that are easily ignited or oxidizing agents that may make an existing fire more intense by fuelling it with oxygen. The presence of large quantities of dry fabric or paper can increase the risk and spread of fires. Faulty electrical wiring can also cause fires. Another source of risk is corrosive chemicals, which can cause serious burns and may react dangerously with other chemicals. Violent and dangerous reactions may be caused by substances which are dangerous such as sodium hydrosulphite when wet. Hot liquids of caustic soda can also lead to scalding accidents. But notwithstanding that, with some reasonable precautions, the small-scale textile workshop or studio can be effectively and efficiently managed without any health and safety challenges.

\section{Ethnographic Account of Sekondi-Takoradi}

The Sekondi-Takoradi Metropolis is a beautiful city comprising the twin cities of Sekondi and Takoradi, with Sekondi as the administrative capital. It occupies the south-eastern part of the Western Region of Ghana; and shares boundaries with Ahanta West, Shama and Komenda-Edina-Eguafo-Abrem Municipalities. It is located on the coast, about 200 kilometres west of Accra, the capital of Ghana with Ahanta and Fanti as the main languages spoken by the indigenes, and fishing as their major occupation. 
A cosmopolitan city with a population of 991,000 people [7], Sekondi-Takoradi which is arguably Western Region's largest city and an industrial and commercial centre, boasts of an outstanding artistic heritage that manifests itself in all aspects of cultural performance and craftworks. Tourists, students and teachers of Takoradi Technical University explore this rich heritage through deep and meaningful engagement with 'opinion leaders', local scholars, artists, dancers (the Kundum dance which is distinctly unique to the people of the area), musicians, painters, sculptors, weavers, writers, and other in-country experts. The leading industries in Sekondi-Takoradi are timber and lumber, shipping and shipbuilding, mining, railways and recently, sweet crude oil. Sekondi-Takoradi lies on the main railway lines to Kumasi, the capital of the Ashanti Region of Ghana. There is a breadth of small to medium-scale production activities in soap making, palm oil, fashion and garments, and textile production which comprises batik, tie-dye, embroidery, $\mathrm{t}$-shirt and fabric printing.

\section{Methodology}

The section discusses the methodology used in gathering data for the study. It includes the method of research, population for the study, sampling procedure and data collection procedures. The qualitative research method is chosen for the study because it seeks to describe a population without attempting to quantifiably measure variables or look to potential relationships between variables. The study is an exploratory exercise into the local textiles production practices that sought for broad questions and collected word-type data that were analysed. The population for the study was 86 and consisted of chemical sellers, fabric dyers and printers. Some establishments studied included Brainy Touch Consult, Dintex Professional Solutions, Gratis Foundation, Sekondi-Road, Sekondi, Deep Calls Chemicals, Market Circle, Takoradi, Fine Touch Batik and Prints-Essikadu-Ketan, Brainy Hands Consult-Sekondi and Ragam Ventures-Essikafo-Abantem No.1 in Takoradi.

The random sampling technique was used. Staff of the establishments mentioned earlier were randomly selected for interviews. Instruments used to undertake the research were questionnaires, interviews and observation. Some suppliers were also contacted at random for interviews to collect data. They were given the chance to freely express their views, from questions posed. However, in the quest to obtain a fair representation of the population, members of staff chosen included both management and supporting staff, examples of which were, sales assistants and dyeing assistants. Researchers' questions were the major instrument used in the study. Copies of questionnaires were prepared for key players who mainly comprised the owners of dyeing and chemical supplying enterprises/set-ups. Question items consisted of both close-ended and open-ended types. Questions and answers were provided, and respondents had to select which answers they thought were appropriate. Adequate time was given to the respondents for their responses, after which before the copies of questionnaire 
were retrieved. Interview guides containing questions were prepared for randomly selected members of staff of the enterprises chosen. The main purpose for this was to collect substantial data and seek clarification (where necessary) on responses received from the questions.

Official visits were made to the proprietors and heads of the enterprises selected to have their consent and permission to use their establishments as case study sites. The method used for analysing the data gathered was the descriptive approach. Statistical tables and charts were also drawn based on data retrieved from respondents. The tables were prepared after the responses from the questionnaires had been edited and tallied.

\section{Findings and Discussion}

The population was chosen because they are highly vulnerable to health hazards as they are exposed to dyes, pigments and their auxiliary chemicals without the use of Personal Protection Equipment (PPEs); and as the majority of accidents are not reported to the Ministry of Manpower and Employment in Ghana, there is limited information about occupational health and safety when it comes to the small-scale textile producing enterprises in Ghana. The following are the presentation of data gathered from the study.

\subsection{Educational Level of Respondents}

The response below in Figure 1 indicates the educational level of all the respondents. It can be clearly seen from the chart that most of the respondents have at least completed basic education. It can, therefore, be inferred that majority of the respondents are educated to a considerable extent and could read and write. It can also be seen that, the number of respondents with Basic Education Certificate is virtually at par with those with First Degree/Equivalent Professional Certificate. Those with SSS/Technical/Vocational Certificates were obviously in the majority. In all the three educational levels, respondents who have not had any formal training on dyes and their auxiliary chemicals were in the majority.

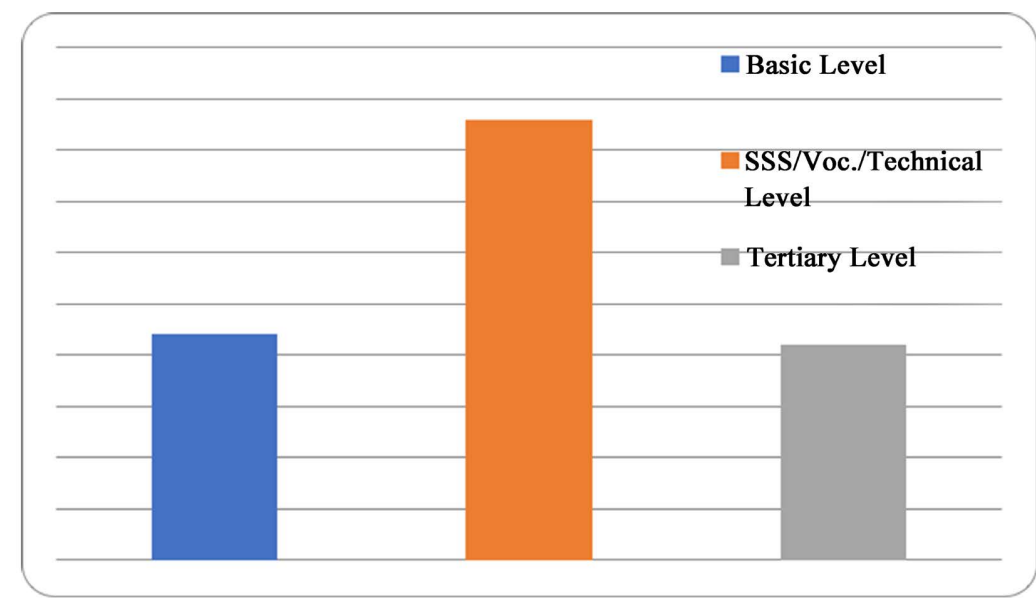

Figure 1. Education level of respondents. Source: Field study, 2020. 
However, they have learnt on the job and to some extent have had some form of experience.

\subsection{Statuses (Positions) of Respondents}

Figure 2 (below) indicates that, $50 \%$ of the respondents are employees, about $30 \%$ are proprietors, and $20 \%$ are either managers or supervisors. It can be seen from the chart that the proprietors are in the minority (30\%) because they employ helping hands to enable them effectively run their set-ups. Those who manage and supervise equal (20\%) and those who do the actual production equal (50\%); therefore, all the employees add up to $70 \%$ of the total number of respondents. The respondents in their entirety indicate that they come into contact with dyes, pigments, auxiliaries and other chemicals at certain stage of production.

They mention that some of the dyes and chemicals they come into contact with are vat dyes, reactive dyes, disperse dyes, natural dyes, printing pigments, soda ash, sodium hydrosulphite, salt, caustic soda and paraffin wax.

Figure 3 illustrates knowledge of material safety information and indicates that eighty five percent of the population studied had no knowledge on Material Safety Information (MSI) that accompany the dyes and other chemicals they come into contact with. Fifteen percent of the population who were mainly chemical dealers and supervisors indicate that they are aware of Material Safety

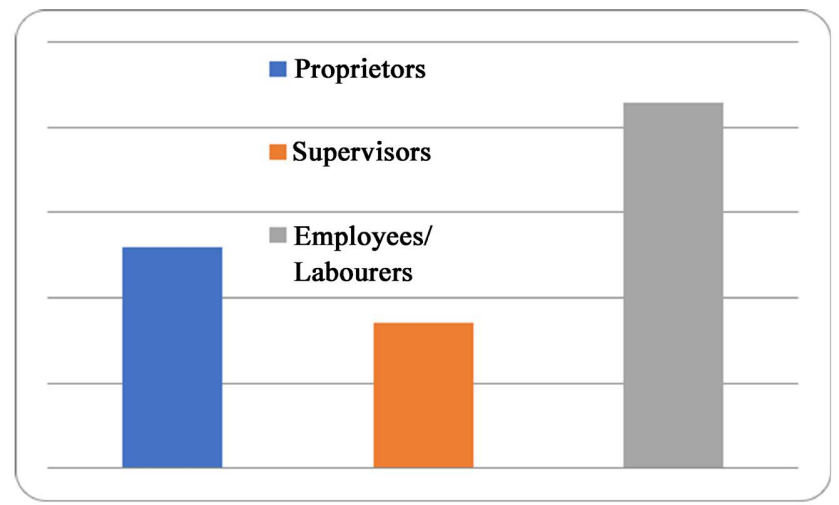

Figure 2. Statues of respondents. Source: Field study, 2020.

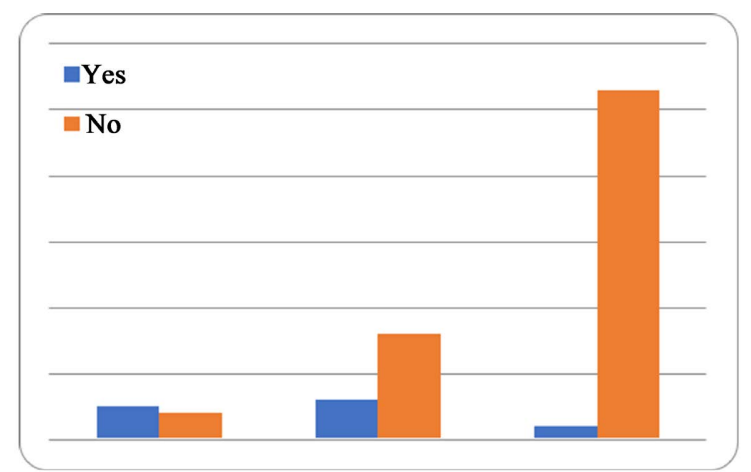

Figure 3. Knowledge of material safety information. Source: Field study, 2020. 
Information on chemicals. What accounted for the lack of knowledge of the MSI by the majority of the producers or labourers is that, most of the dyes and chemicals they use are repackaged by the dealers who break bulk to retail them in smaller packages. The new packages do not carry labels and for that matter MSI. Figure 4 contains packages of dyes and chemicals in original containers with lables and Figure 5 is an example of a repackaged vat dye in a polythene bag.

From the analysis it can be deduced that, because chemical suppliers sell their wares in bulk (wholesale), their physical contacts with chemicals are often less or minimal than that of chemical sellers who usually do retailing in smaller quantities and also fabric dyers, who physically make use of them in their production processes. These account for the reason why chemical suppliers do not often have unpleasant accidents when handling chemicals. Even though most of them had encountered critical incidences; they were minimal in terms of frequency, as

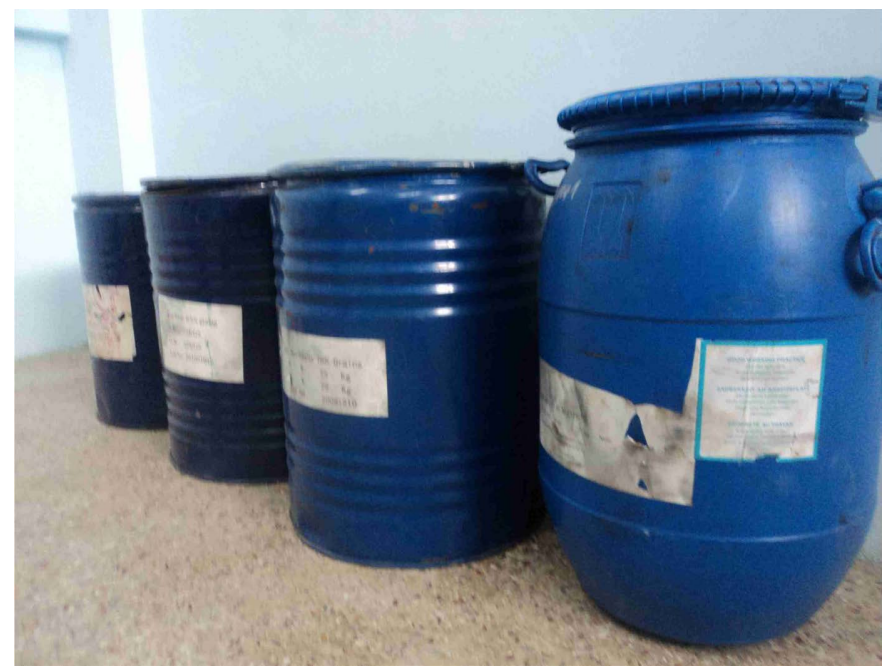

Figure 4. Textile dyes in labelled containers. Source: Field study, 2020.

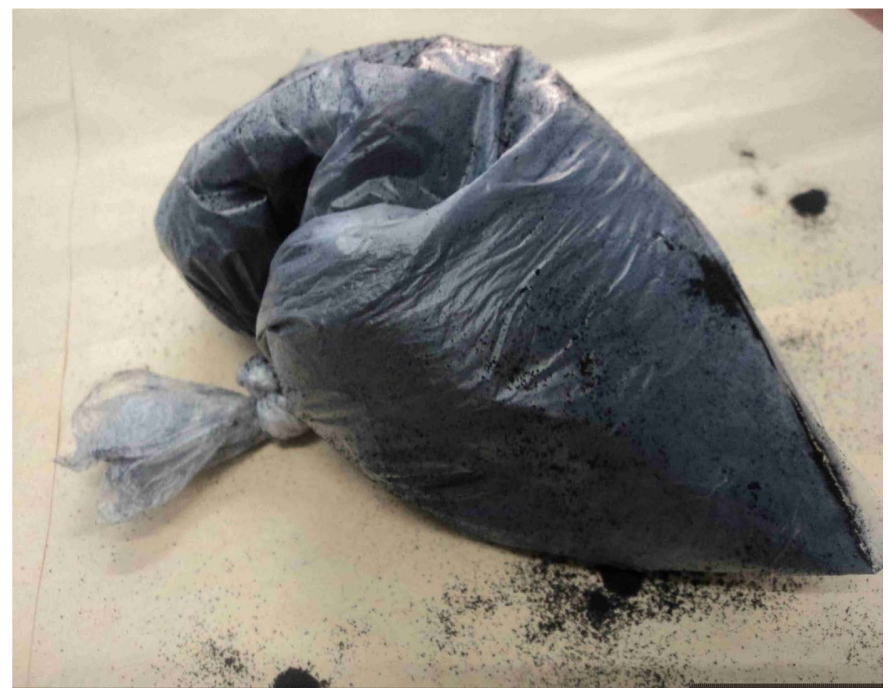

Figure 5. Dye in polythene bag. Source: Field study, 2020. 
compared to that of chemical sellers and fabric dyers/printers. The high frequency in terms of hazardous incidents was a result of the absence of MSDS/MSI at these set-ups. The reason is that MSDS/MSI provides pertinent information about the dye or chemical. For example, chemical name, its properties and safe storage protocols, its handling and disposal. It further provides information on first aid as well as fire-fighting and preventive measures. Figure 6 indicates that dealers of dyes and textile chemicals, managers of small-scale textile firms and workers don't always observe the safety precautions on chemical application in their production processes.

It was also ascertained that material safety Information on chemical packages or containers is very complex to understand by most of the users identified during the study. See Figure 7 and Table 1.

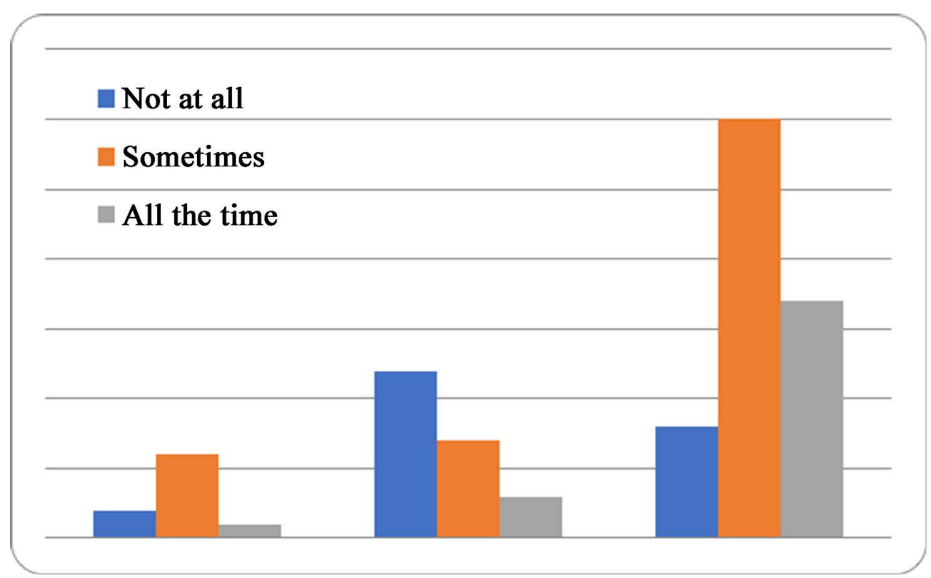

Figure 6. Observation of safety precautions on chemical usage. Source: Field study, 2020.

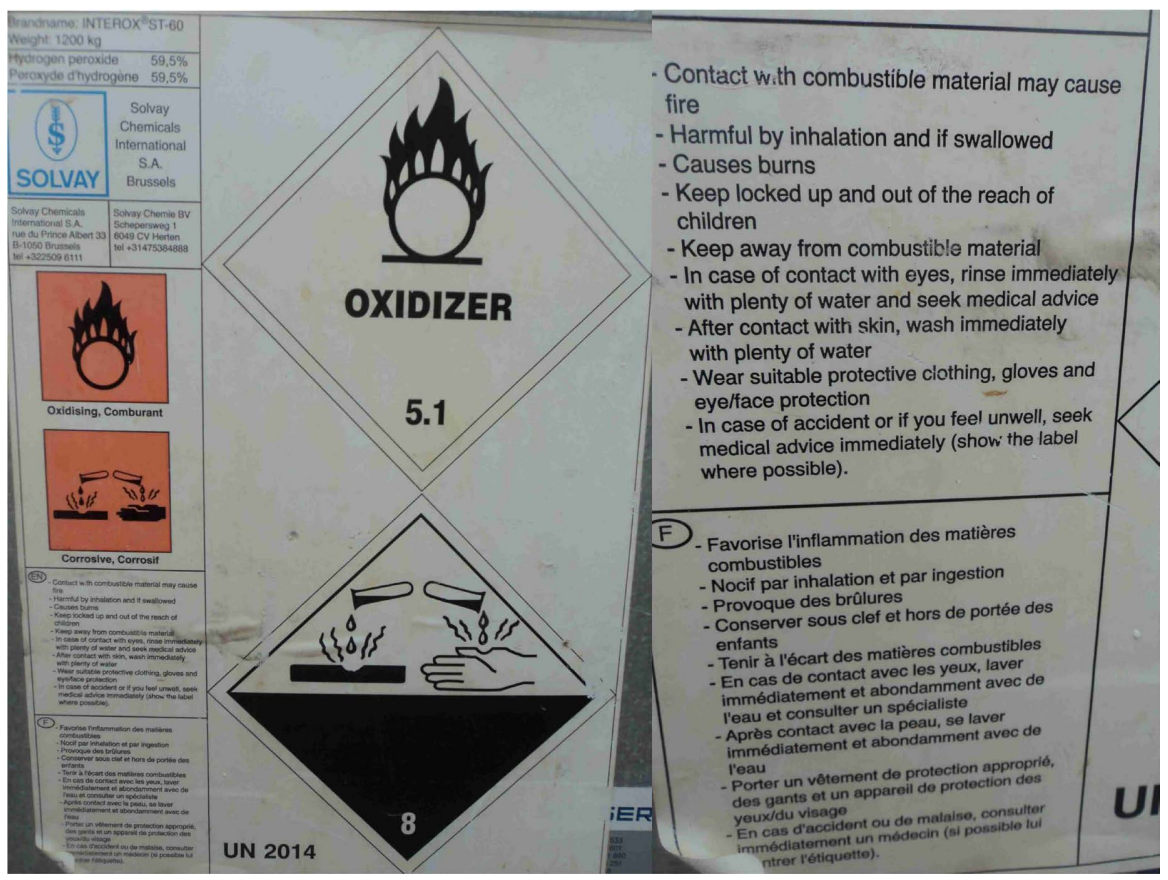

Figure 7. Material safety information on a chemical container. Source: Field study, 2020. 
Table 1. Summary of material safety information.

\begin{tabular}{|c|c|}
\hline \multirow[t]{4}{*}{ HAZARD SYMBOLS } & EXPLANATION \\
\hline & $\mathrm{E}$ \\
\hline & Explosive \\
\hline & Chemical that explodes \\
\hline & $\mathrm{O}$ \\
\hline & Oxidizing \\
\hline & Chemicals that react exothermically with other chemicals. \\
\hline & $\mathrm{F}+$ \\
\hline & Extremely Flammable \\
\hline & Chemical that has an extremely low flash point and boiling \\
\hline & point, and gases that catch fire in contact with air. \\
\hline & $\mathrm{F}$ \\
\hline & Highly Flammable \\
\hline & Chemicals that may catch fire in contact with air, only \\
\hline & need brief contact with an ignition source, have a very low \\
\hline & flash point or evolve highly flammable gases in contact \\
\hline & $\mathrm{T}+$ \\
\hline & Very toxic \\
\hline & Chemicals that at very low levels cause damage to health. \\
\hline & $\mathrm{T}$ \\
\hline & Toxic \\
\hline & Chemicals that at low levels cause damage to health. \\
\hline & Carc Cat 1 \\
\hline & Category 1 \\
\hline & carcinogens \\
\hline & Chemicals that may cause cancer or increase incidence. \\
\hline & Carc Cat 2 \\
\hline & Category 2 \\
\hline & carcinogens \\
\hline & Carcinogens \\
\hline & Carc Cat 3 \\
\hline & Category 3 \\
\hline & carcinogens \\
\hline & Carcinogens \\
\hline & Muta Cat 1 \\
\hline & Category 1 \\
\hline & mutagens \\
\hline & $\begin{array}{l}\text { Chemicals that induce heritable genetic defects or increase } \\
\text { their incidence. }\end{array}$ \\
\hline & Muta Cat 2 \\
\hline & Category 2 \\
\hline & mutagens \\
\hline & $\begin{array}{l}\text { Chemicals that induce heritable genetic defects or increase } \\
\text { their incidence. }\end{array}$ \\
\hline
\end{tabular}




\section{Continued}

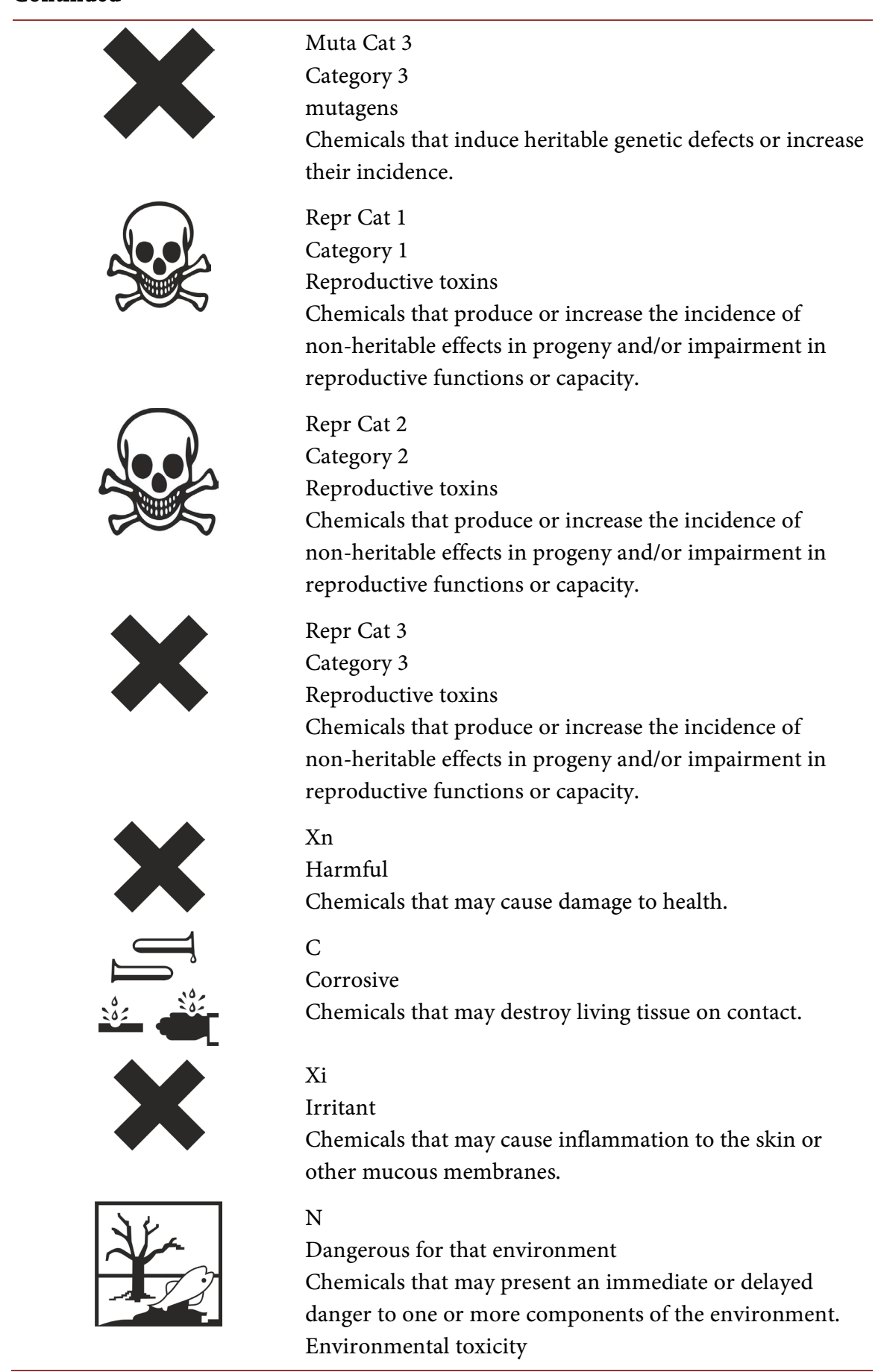

Source: Field study, 2020.

A variety of specialized safety clothing and equipment is available for use as protection when handling or working with dyes and chemicals. Ideally all personnel in small-scale textile production should be familiar with this equipment. Aprons are provided for protection from splashes. Face shields are used when there is a potential for splashing, spattering or spraying of chemicals or solutions to the face. Skin contact is a potential source of exposure to toxic materials and 
biohazard so it is important to wear the right glove for proper protection. Safety glasses and goggles are used for eye protection and should be worn when making solutions and distributing solutions from one container to another. Overall or overcoat is worn to prevent contact with dirt and minor chemical splashes. Nose masks should be worn when making solutions in an enclosed area. According to the study, 50\% percent of the population studied sometimes use protective or safety equipment while $26 \%$ do not use them at all. Twenty four percent of the respondents indicated that they use protective and safety equipment at all times and that is reflected in Figure 8.

\subsection{Interventions}

This study is strongly advocating that, chemical dealers who break bulk must stick precaution labels on the retail packages to warn or inform prospective users. The study has put forth a simple and cheap way to attach labels to repackaged dyes as shown in Figure 9 and Figure 10. Textile producers must be of a necessity

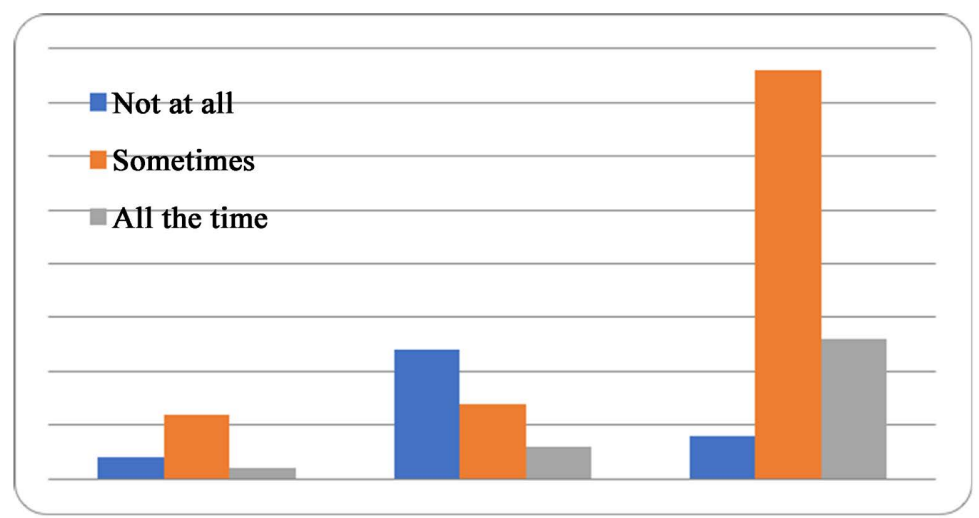

Figure 8. Usage of safety equipment when handling chemicals. Source: Field study, 2020.

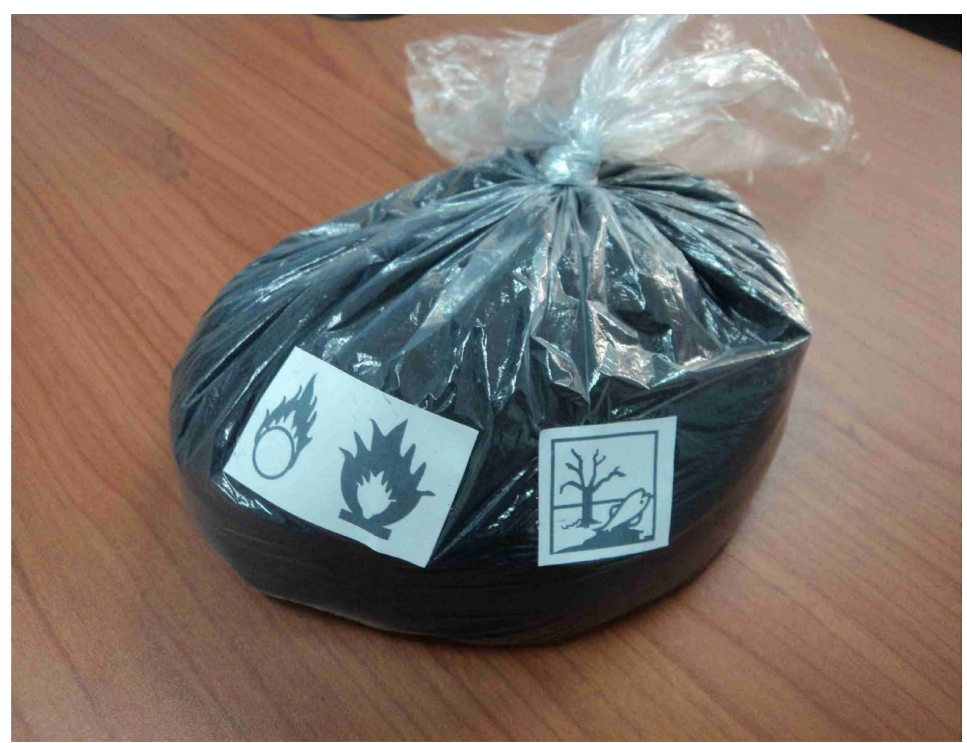

Figure 9. Repackaged vat dye in polythene with warning stickers. Source: Field study, 2020. 

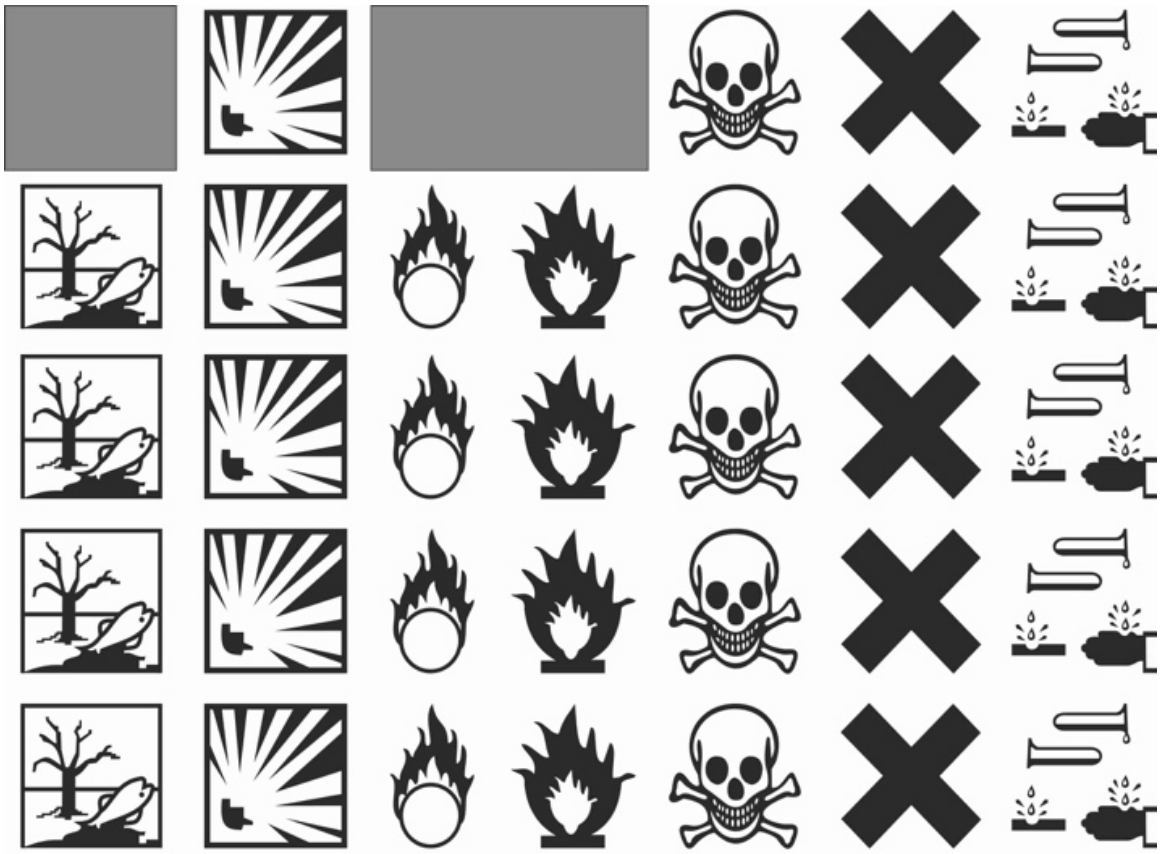

Figure 10. Sampler of simple stickers for repackaged dyes and chemicals. Source: Field study, 2020.

use appropriate safety equipment when using chemicals. Safety education must be organised periodically by managers of small-scale textile enterprises. This must also include first aid procedures such as the immediate steps to take when there is an accident. All textile workers must acquaint themselves with the material safety data and danger symbols and their corresponding safety gears as shown in Figure 11. This material safety information must be displayed at vantage locations at their enterprises to serve as a constant reminder of safe practices. In the long term, there should be a liaison between the Environmental Protection Agency of Ghana and the small-scale textile producers as to the appropriate ways of disposing chemicals after usage. This is an area that would require much attention in terms of consultation and capacity building. This must be championed by Environmental Protection Agency of Ghana.

\section{Conclusions}

The majority of the dyestuffs currently used in textile dyeing and finishing has not proven to be harmful in the levels of exposure that workers face. With longterm or accidental over exposure, there can be potential health hazards and all dyes and chemicals must, therefore, be handled or applied with extreme caution. As indicated earlier, the most common hazard of reactive dyes is respiratory problems caused by inhalation of dye particles. This is called respiratory sensitization and symptoms include itching, watery eyes, sneezing and symptoms of asthma such as coughing and wheezing. Perhaps the most prevalent health problem associated with dyeing and finishing processes arises from exposure to chemicals acting as irritants. These may cause skin irritation, itchy or blocked noses, 


\section{SAFETY PRECAUTION CHART FOR SMALL SCALE TEXTILE PRODUCERS}

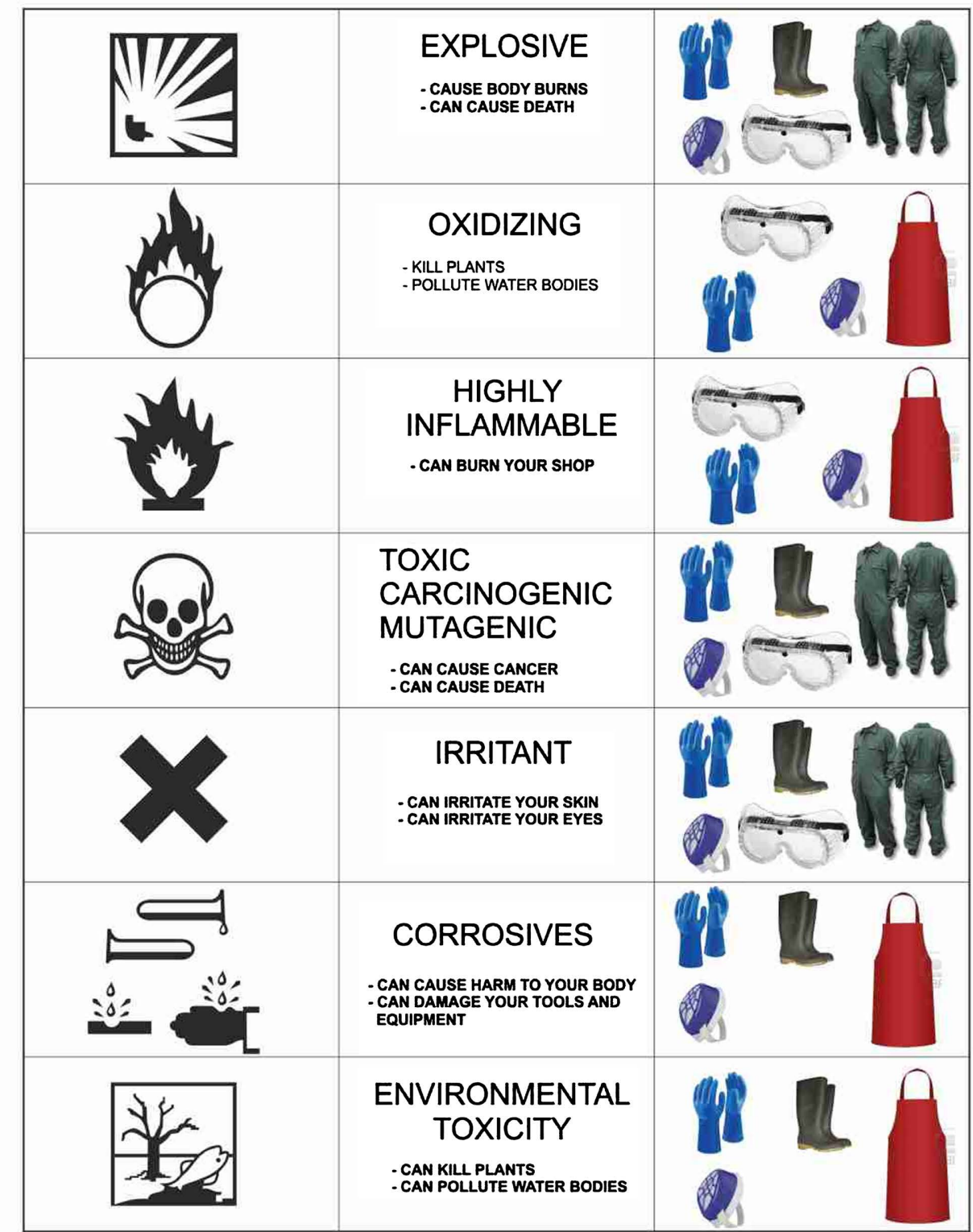

COMPILED BY ERIC BRUCE-AMARTEY JNR. AND RICHARD ACQUAYE, DEPARTMENT OF TEXTILE DESIGN AND TECHNOLOGY, TAKORADI POLYTECHNIC - TAKORADI

Figure 11. Simplified safety chart for small scale textiles producers. Source: Field study, 2020.

sneezing and sore eyes. They include formaldehyde-based resins, ammonia, acetic acid, some shrink-resist chemicals, some optical whiteners, soda ash, caustic soda and bleach. Certain reactive, vat and disperse dyes are also recognized as skin sensitizers. Fire hazards may arise from the use of flammable liquids that are easily ignited or oxidizing agents, which may make existing fire intense by fuelling it with oxygen. Corrosive chemicals can cause serious burns and may react 
dangerously with other chemicals. Violent reactions may be caused by substances such as sodium hydrosulphite which are dangerous when wet. Hot liquids also cause many scalding accidents.

In concluding this study, the following summary of corrective measures is put forward. Dyes, chemicals and other auxiliaries should be stored in a separate work area and access to this area should be limited to trained personnel. The storage area should be kept relatively cool and dry, and all items must be recorded in log books and clearly labelled in the language used by the handlers. It is important to know what chemicals one has and their compatibility because when mixed, certain chemicals may react in a hazardous way; they may react violently, generate much heat or evolve toxic gases. Textile chemicals must, therefore, be carefully stored to avoid such reactions. Some substances, such as sodium hydrosulphite, may react violently if contaminated with a small quantity of water, so should be kept covered and off the floor. Small-scale textile dyeing is an essential contributor to the growth of the Ghanaian textile industry. Its diverse operations can also have significant impacts on the local environment and present health and safety risks to its workforce. It is, therefore, very imperative on the part of managers and proprietors of small-scale textile establishments to consider the potential safety hazards and environmental impacts in the planning phase which might be costly and difficult to mitigate at a later stage.

Material Safety Data Sheets are an important tool in achieving good health and safety standards. They provide information on names of chemicals, their properties, safe storage, handling and disposal. Material safety data information should be consulted and followed for all chemicals received by the set-ups and workers should be made aware of the contents of such information. If a supplier does not provide MSDS automatically they must be requested. To maintain high standards of health and safety, the managers should regularly review and revise their health and safety tips to keep workers safe and prevent avoidable accidents. It is envisaged that, just as small holder textile producers form guilds to meet huge demands just before the industrial revolution in Europe, small-scale textile producers in Ghana could put in place measures that would be more sustainable and drive them into large scale production. Hence, appropriate use of chemicals and other hazardous substances must be encouraged for a safe and more efficient work environment.

\section{Conflicts of Interest}

The authors declare no conflicts of interest regarding the publication of this paper.

\section{References}

[1] Ahene-Nunoo, N. (2019) Cottage Textile Production in Ghana. Kyle and Steff Publications Inc., New York

[2] Ahmed, S.T. (2002) Health and Safety in the Textile Dyeing Industry. Stockholm Environment Institute and Bangladesh Centre for Advanced Studies, Dhaka, Bangladesh. 
[3] Lellis, B., Fávaro-Polonio, C.Z., Pamphile, J.A. and Polonio, J.C. (2019) Effects of Textile Dyes on Health and the Environmentand Bioremediation Potential of Living Organisms. Biotechnology Research and Innovation, 3, 275-290. https://doi.org/10.1016/j.biori.2019.09.001

[4] Afena, A., Boateng, D., Darkwah, L. and Adjaottor, A. (2021) Decolourisation of Textile Wastewater by Dye Degrading Microorganisms Isolated from Textile Effluent. Journal of Environmental Protection, 12, 767-783. https://doi.org/10.4236/jep.2021.1210046

[5] Health and Safety Executive (2020) Dyes and Dyeing. Health and Safety Executive (HSE). https://www.hse.gov.uk/textiles/dyes-dyeing.htm

[6] Suna, N., Tewes, T., Luch, A. and Pirow, R. (2020) A Scientific Review of Colorful Textiles. Journal of Consumer Protection and Food Safety, 16, 5-17.

https://doi.org/10.1007/s00003-020-01301-1

[7] Ghana Statistical Service (2021) Ghana 2021 Population and Housing Census (Volume 1). Ghana Statistical Service, Accra. 